\title{
Violation of eating expectancies does not reduce conditioned desires for chocolate
}

Citation for published version (APA):

van den Akker, K., van den Broek, M., Havermans, R. C., \& Jansen, A. (2016). Violation of eating expectancies does not reduce conditioned desires for chocolate. Appetite, 100(1), 10-17. https://doi.org/10.1016/j.appet.2016.02.004

Document status and date:

Published: 01/05/2016

DOI:

10.1016/j.appet.2016.02.004

Document Version:

Publisher's PDF, also known as Version of record

Document license:

Taverne

Please check the document version of this publication:

- A submitted manuscript is the version of the article upon submission and before peer-review. There can be important differences between the submitted version and the official published version of record.

People interested in the research are advised to contact the author for the final version of the publication, or visit the DOI to the publisher's website.

- The final author version and the galley proof are versions of the publication after peer review.

- The final published version features the final layout of the paper including the volume, issue and page numbers.

Link to publication

\footnotetext{
General rights rights.

- You may freely distribute the URL identifying the publication in the public portal. please follow below link for the End User Agreement:

www.umlib.nl/taverne-license

Take down policy

If you believe that this document breaches copyright please contact us at:

repository@maastrichtuniversity.nl

providing details and we will investigate your claim.
}

Copyright and moral rights for the publications made accessible in the public portal are retained by the authors and/or other copyright owners and it is a condition of accessing publications that users recognise and abide by the legal requirements associated with these

- Users may download and print one copy of any publication from the public portal for the purpose of private study or research.

- You may not further distribute the material or use it for any profit-making activity or commercial gain

If the publication is distributed under the terms of Article $25 \mathrm{fa}$ of the Dutch Copyright Act, indicated by the "Taverne" license above, 


\title{
Violation of eating expectancies does not reduce conditioned desires for chocolate
}

\author{
Karolien van den Akker ${ }^{*}$, Myrr van den Broek, Remco C. Havermans, Anita Jansen \\ Faculty of Psychology and Neuroscience, Department of Clinical Psychological Science, Maastricht University, P.O. Box 616, 6200 MD Maastricht, The \\ Netherlands
}

\section{A R T I C L E I N F O}

\section{Article history:}

Received 9 October 2015

Received in revised form

28 January 2016

Accepted 2 February 2016

Available online 4 February 2016

\section{Keywords:}

Appetitive conditioning

Instructed extinction

Extinction

Spontaneous recovery

Expectancy violation

Cue exposure therapy

\begin{abstract}
A B S T R A C T
Although eating desires can be easily learned, their extinction appears more difficult. The present twosession study aimed to investigate the role of eating expectancies in the short and longer-term extinction of eating desires. In addition, the relationship between eating desires and conditioned evaluations was examined to test whether they might share a similar mechanism. It was hypothesized that the shortterm extinction of eating desires would be more successful after the disconfirmation of eating expectancies (instructed extinction or IE), while resulting in worse longer-term extinction because omission of the food reward during extinction is not surprising. In contrast to the hypotheses, it was found that IE had no effect on the short-term and longer-term extinction of eating desires. Eating desires correlated with conditioned evaluations only to some extent. It is concluded that eating expectancies do not mediate the short-term extinction of conditioned eating desires. In addition, their longer-term extinction does not appear to be facilitated by a greater violation of eating expectancies. This suggests that it might not be necessary to focus on expectancy violation in cue exposure therapy to reduce eating desires.
\end{abstract}

(C) 2016 Elsevier Ltd. All rights reserved.

\section{Introduction}

Obesity prevalence has increased substantially over the last decades, most western countries now reporting approximately $10-35 \%$ of their adult population to be obese (Berghofer et al., 2008; Ogden, Carroll, Kit, \& Flegal, 2014). One important contributor to obesity is the "obesogenic" environment, in which omnipresent food cues signal the availability of palatable, high-calorie foods. Exposure to these cues can elicit physiological and psychological reactions, including an increased desire to consume the food (Jansen, 1998). These cue-elicited eating desires are thought to stimulate overeating and weight gain (Fedoroff, Polivy, \& Peter Herman, 2003; Jansen, Havermans, \& Nederkoorn, 2011), and appear heightened in overweight individuals and in those with eating psychopathology (Ferriday \& Brunstrom, 2011; Jansen et al., 2003; Karhunen, Lappalainen, Tammela, Turpeinen, \& Uusitupa, 1997). This highlights the need for investigating the etiology of cued eating desires, as well as finding ways to effectively tackle them.

\footnotetext{
* Corresponding author.

E-mail address: karolien.vandenakker@maastrichtuniversity.nl (K. van den Akker).
}

It is thought that learning processes play an important role in cue-elicited eating desires. For instance, the sight and smell of food are thought to have become conditioned stimuli (CSs) predictive for food intake (unconditioned stimulus or US) through repeated CSUS pairings (Jansen, 1998). As a result, a CS (food cue) can elicit conditioned appetitive responses (CRs) such as a heightened desire to eat, increased salivation, and an explicit eating expectancy. Moreover, learning theory predicts that these CRs extinguish after repeated exposures to the CS alone. Thus, theoretically, after repeated exposure to the sight and smell of palatable food without consumption, conditioned responses such as desires to eat should decline. Such successful extinction of responses to food cues is thought to increase one's ability to abstain from eating, and ultimately, result in improved weight loss success (Jansen, 1998; Jansen et al., 2011; Jansen, Stegerman, Roefs, Nederkoorn, \& Havermans, 2010; Wardle, 1990). In support, the few studies conducted on cue exposure therapy (CET), in which overweight individuals or those with eating psychopathology are repeatedly exposed to food cues without eating, indeed suggest CET to be effective in reducing cue-elicited cravings and eating binges (e.g., Boutelle et al., 2014; Jansen, Broekmate, \& Heymans, 1992; Jansen, Van Den Hout, De Loof, Zandbergen, \& Griez, 1989; Martinez-Mallén et al., 2007; Schyns, Roefs, Mulkens, \& Jansen, 2016; Toro et al., 2003). Despite 
these very promising findings, the evidence for a superiority of CET over control treatments at follow-up is mixed (Boutelle et al., 2014; Jansen et al., 1992). Since CET is rooted in learning theory, it might be optimized by studying the mechanisms that underlie the (longterm) extinction of appetitive responses to food cues.

Extinction can be studied using conditioning paradigms, in which cue-elicited eating desires and eating expectancies are first established by repeatedly pairing a cue (CS) with a US (food) (e.g., Bongers, van den Akker, Havermans, \& Jansen, 2015; Van den Akker, Havermans, Bouton, \& Jansen, 2014; Van Gucht, Vansteenwegen, Van den Bergh, \& Beckers, 2008a). This acquisition phase is followed by an extinction phase, during which repeated CS - no US pairings occur. Findings suggest that eating desires can be quickly acquired, but only when a participant is consciously aware of the CS-US contingency (i.e., when reporting heightened US expectancies upon CS presentation) (Van den Akker, Jansen, Frentz, \& Havermans, 2013). Thus, during acquisition, US expectancies are likely essential for developing cued eating desires. During extinction however, the two responses can diverge: even when eating expectancies reduce, eating desires can remain heightened (Van Gucht, Vansteenwegen, Beckers, \& Van den Bergh, 2008b). These divergent extinction patterns suggest an involvement of separate response systems that are differentially affected by extinction. Specifically, it may be that eating expectancies relate more to an anticipatory response system, preparing the organism for an incoming stimulus (Van Gucht, Vansteenwegen, Van den Bergh, \& Beckers, 2008b). In contrast, regarding the desire to eat, it has been noted that its resistance to extinction resembles extinction in evaluative conditioning: conditioned evaluations do not extinguish easily as well (Baeyens, Crombez, Van den Bergh, \& Eelen, 1988; Van Gucht et al., 2008b). It might be that CS evaluations are based on the mere activation of the US representation in memory, i.e., reflecting a mere referential learning in which the CS "makes one think of" the US in the absence of actual eating expectancies (Hermans, Vansteenwegen, Crombez, Baeyens, \& Eelen, 2002; Baeyens, Eelen, Crombez, \& Van den Bergh, 1992). This activation of the US representation could also be sufficient for experiencing heightened eating desires (Van Gucht, Baeyens, Vansteenwegen, Hermans, \& Beckers, 2010). Extinction may have more impact on response systems that prepare an individual for an incoming stimulus than on systems that are based on the mere activation of the US representation in memory (Van Gucht et al. 2008b; see also Luck \& Lipp, 2015; Sevenster, Beckers, \& Kindt, 2012), causing eating desires and CS evaluations to extinguish more slowly than US expectancies.

However, there is also evidence suggesting a closer relationship between expectancies and eating desires during extinction. For instance, although it indeed seems difficult to completely extinguish cue-elicited eating desires, their extinction can be achieved to a certain extent (Van den Akker et al., 2014; Van den Akker et al., 2015). This pattern is, in fact, very similar to the extinction of US expectancies: although expectancies diminish, they usually do not show complete extinction either (Van den Akker et al., 2014; Van den Akker et al., 2015; Van Gucht et al., 2008b). In addition, in a conditioning study conducted in smokers, explicit disconfirmation of acquired US expectancies (i.e., "instructed extinction" or IE) immediately eliminated cue-elicited craving for cigarettes, suggesting that expectancies acted as a mediator for cue-elicited cigarette craving (Field \& Duka, 2001). Thus, it seems possible that the lack of complete extinction of eating desires during extinction in previous studies was caused by a lack of complete extinction of eating expectancies, rather than by the involvement of separate response systems. A complete and immediate elimination of acquired eating expectancies by IE can help determine how closely food cravings and US expectancies are related: if conditioned cravings were to disappear immediately after CS-US disconfirmation, this would provide evidence for a mediating role of expectancies in the extinction of eating desires, and against the involvement of different response systems. Conversely, if conditioned cravings remain heightened despite an elimination of expectancies, this would provide evidence against a mediating role of expectancies in the extinction of eating desires, and would provide additional support for the idea of different response systems underlying the extinction of US expectancies and conditioned desires.

Extinction performance during one experimental session does not need to be predictive for longer-term extinction learning. New memories require time to consolidate (McGaugh, 2000), which is why actual learning is best tested at a later point in time. In case of IE, one could expect worse longer-term extinction learning, despite a possibly better short-term extinction performance. One reason for this might be the altered degree of "surprise" of non-occurrence of the US during extinction. Surprise, or violation of US expectancies, is thought to play a major role in (extinction) learning: a smaller discrepancy between expected and actual occurrence of the US should result in poorer (inhibitory) learning (Craske, Treanor, Conway, Zbozinek, \& Vervliet, 2014; Rescorla \& Wagner, 1972). After IE, the US omission that occurs during extinction is not very surprising, therefore possibly resulting in worse longer-term extinction learning. This would have implications for cue exposure therapy. If a reduction in US expectancies prior exposure (extinction) sessions results in worse extinction learning, cue exposure therapy might benefit from maximizing these expectancies prior to an exposure session - i.e., heightening expectancies for the US (eating) to occur.

The primary aim of the present study was to evaluate the role of US expectancies in the short and longer-term extinction of conditioned eating desires. To examine this, extinction performance in an IE condition (i.e., receiving explicit disconfirmation of the acquired CS-US contingencies before extinction) was compared with a "normal" extinction condition (no extinction instructions) on two subsequent days. It was expected that IE would speed up the shortterm extinction of eating desires relative to a normal extinction procedure, while resulting in worse extinction learning, as reflected by a greater spontaneous recovery (the recovery of responding that occurs after the mere passage of time) (Pavlov, 1927; Rescorla, 2004) and slower re-extinction during test after a 24 h delay. Alternatively, it may be that eating desires are more closely related to evaluations of the CS rather than to US expectancies because they may share a similar mechanism. To examine this possibility conditioned CS evaluations were measured before and after each extinction session, and correlations between US expectancies, eating desires, and CS evaluations were assessed.

\section{Methods and materials}

\subsection{Participants}

48 participants took part in the study, of which two participants were replaced by additional participants because they did not show awareness of the CS-US contingency (i.e., they did not report clear differential US expectancies towards the end of acquisition), and one other participant because she did not show up for the second session. Participants were eligible to participate in the study if they were 1 st or 2 nd year undergraduate female students, between 17 and 25 years old, proficient in Dutch, and had indicated to like chocolate. Further, care was taken that no participant had previously participated in an appetitive conditioning study. To standardize hunger, participants were instructed to have a small meal two hours prior to each session and to refrain from consumption thereafter (only the drinking of water was allowed). As a cover 
story, participants were told the study was about the memory of taste. Participants received either a voucher worth $€ 12.50$ or course credit for participation. The study was approved by the local ethical committee.

\subsection{Measurements}

\subsubsection{US expectancy and desire to eat}

$100 \mathrm{~mm}$-Visual Analogue Scales (VAS) were used to assess expectancy to receive chocolate ('To what extent do you expect this box to contain chocolate at this moment?') and subjective desire for chocolate ('When looking at this box, how strong is your desire for chocolate at this moment?') (in this order). Ratings ranged from 0 (certainly expect this box not to contain chocolate/no desire at all) to 100 (certainly expect this box to contain chocolate/very strong desire).

\subsubsection{CS evaluations}

Evaluations for the $\mathrm{CS}+$ and $\mathrm{CS}$ - were assessed using two VAS ('How pleasant do you find the box depicting the elephant/fish?') (in this order). Ratings ranged from 0 (not pleasant at all) to 100 (extremely pleasant).

\subsubsection{Hunger}

To be able to control for possible group differences in hunger, participants filled in a VAS ('How hungry are you at this moment?') ranging from 0 (not hungry at all) to 100 (extremely hungry).

\subsubsection{US liking}

To be able to control for possible group differences in the liking of the chocolate (the US) used, participants filled in a VAS ('How much did you like the chocolate?'), ranging from 0 (not at all) to 100 (extremely).

\subsubsection{Dutch Eating Behaviour Questionnaire (DEBQ; Van Strien, \\ Frijters, Bergers, \& Defares, 1986)}

The DEBQ was administered to be able to control for possible group differences in eating styles. This 33-item questionnaire provides a measure of external eating (10 items), emotional eating (13 items), and restraint (10 items). Each item is scored on a 5-point scale, ranging from "never" to "very often", higher scores indicating a higher degree of emotional or external eating, or restraint.

All questionnaires were administered in Dutch.

\subsection{Stimuli}

US: A small piece of Belgian milk chocolate (approximately 1.3-1.5 g, Rousseau) served in a small cup served as US. The USs were kept out of sight of the participants.

CS: Two children's jewelry boxes served as CSs, and contained the US in case of a CS + trial. One box depicted elephants ("Elmer the Patchwork Elephant') and had coloured squares and yellow linings, and the other depicted fish ('The Rainbow Fish') and was blue. Which box served as CS + and CS - was counterbalanced across conditions.

\subsection{Design and procedure}

Participants were randomly assigned to one of two conditions: instructed extinction (IE) or normal extinction (NE), which differed only in instructions that were given after the acquisition phase. Participants were individually seen on two sessions, the second session always taking place exactly $24 \mathrm{~h}$ after the first session. Testing took place between 11 AM and 6 PM.

\subsubsection{Session 1}

After arrival, participants gave written consent for participation and rated their hunger. Next, they were shown the boxes and were instructed that one of the boxes would sometimes contain something they would eat, whereas the other box would never contain anything. Participants repeated this information once. After this, the conditioning procedure started.

Acquisition: During acquisition training, all participants received five CS+ and five CS - trials. A trial proceeded as follows: a box (CS+ or $\mathrm{CS}_{-}$) was placed in front of the participant for $10 \mathrm{~s}$ and she was instructed to look at the box. Next, she rated her US expectancy and desire to eat, after which she opened the box. In case of a CS+ trial, the box contained the US which the participant consumed. In case of a CS - trial, the box did not contain anything. The participant closed the box and an inter-trial interval of 20 s started, after which the next trial began. All instructions given during the trials were pre-recorded. Trials were presented in a random order, with the restriction that no more than two consecutive trials were of the same trial type $(\mathrm{CS}+$ or $\mathrm{CS}-)$.

Pilot testing suggested that the interruption in the conditioning procedure after acquisition (which was necessary for instructed extinction and to measure conditioned evaluations) unwantedly diminished responses on the first extinction trial in the NE condition, likely because some participants suspected the "rules" had changed. Therefore, two VAS (US liking and US creaminess) were given to the participant after the first two $\mathrm{CS}+$ trials had been completed, in order for participants to learn that an interruption would not be predictive for a discontinuation of CS-US pairings. These VAS were introduced in a manner similar to the interruption in the conditioning procedure after acquisition (see below).

CS evaluations and manipulation: After acquisition, CS evaluations were assessed in both conditions. The VASs were introduced as follows: "We now briefly interrupt the study so you can fill in this question." Only in case of IE, this was followed by the instruction: "Please pay close attention; you will now receive a very important instruction. From now on, none of the boxes will contain chocolate. It is important for you to understand and remember this. Could you repeat this instruction?" Next, in both conditions, the participant was told: "Thank you. The study will now continue". After this, the extinction phase started.

Extinction: All participants received a similar extinction procedure, during which $12 \mathrm{CS}+$ and $12 \mathrm{CS}$ - trials were presented. Trials proceeded as during acquisition, with the exception that no USs were provided. Whether the first extinction trial was a $\mathrm{CS}+$ or $\mathrm{CS}-$ was counterbalanced across conditions.

After extinction, CS evaluations, a bogus memory questionnaire, and the participant's time of pre-experimental food intake were assessed.

\subsubsection{Session 2}

After arrival in the laboratory, participants rated their current hunger, and CS evaluations were assessed. Next, participants received a second extinction phase.

Re-extinction: Participants received $12 \mathrm{CS}+$ and $12 \mathrm{CS}$ - trials (no USs were given). Trials proceeded as during the previous phases. Whether the first extinction trial was a CS+ or CS- was counterbalanced across conditions.

After re-extinction, CS evaluations, the participant's suspicion about the study's hypothesis, their time of pre-experimental food intake, the DEBQ and the participant's height and weight were assessed.

\subsection{Data reduction and statistical analyses}

Differential acquisition, extinction, and re-extinction of the 
desire to eat and US expectancy over time and across conditions were analyzed using repeated-measures ANOVAs for each phase of the experiment (acquisition, extinction, and re-extinction). This resulted in 2 (Condition: IE vs. NE) $\times 2$ (CS-type: CS+vs. CS-) $\times 5 /$ 12/12 (Acquisition Trial/Extinction Trial/Re-extinction Trial) repeated-measures ANOVAs, including CS-type (CS) and Trial (T) as within-subjects factors and Condition (C) as between-subjects factor. Spontaneous recovery was analyzed using 2 (Condition: IE vs. NE) $\times 2$ (CS-type: CS+ vs. CS-) $\times 2$ (Trial: EXT12 vs. RE-EXT1) RM ANOVAs. To test the immediate effects of our manipulation, 2 (Condition: IE vs. NE) $\times 2$ (CS-type: CS+ vs. CS-) $\times 2$ (Trial: ACQ5 vs. EXT1) ANOVAs were conducted, as well as a paired t-test for the IE condition on the differentiation on the first extinction trial. Acquisition and extinction of differential CS evaluations were assessed using repeated-measures ANOVAs as well, using CS and T (acquisition, extinction, pre re-extinction, post re-extinction) as within-subjects variables, and $\mathrm{C}$ as between-subjects variable. Finally, to assess how strongly the different responses were associated, differential responses (i.e. $\mathrm{CS}+$ minus $\mathrm{CS}-$ ) were calculated for CS evaluations, US expectancies, and eating desires, before and after each extinction phase (expectancies and desires: ACQ5; EXT12; RE-EXT1; RE-EXT12; evaluations: ACQ; EXT; RE-EXT PRE; RE-EXT POST), and correlational analyses on these responses were performed. Greenhouse-Geisser epsilon corrections are reported for all repeated-measures analyses whenever sphericity was violated.

\section{Results}

Participants characteristics are displayed in Table 1. Because baseline hunger on session 1 differed across the conditions, it was included as a centered covariate in the analyses. Since hunger did not influence patterns of conditioned responding in any of the phases, all ps $>.05$, in the final analyses, hunger was not included.

\subsection{US expectancy}

Acquisition: Participants learned to expect to receive chocolate when presented with the CS + , as indicated by a significant CS $\times \mathrm{T}$ interaction, $F(2.89,132.84)=82.81, p<.001, \eta_{\mathrm{p}}^{2}=.64$, with no differences across conditions $(\mathrm{CS} \times \mathrm{T} \times \mathrm{C}), F<1$ (see Fig. 1). This resulted in a significant CS+ vs. CS- differentiation on trial $5, F(1$, $46)=1550.71, p<.001, \eta_{\mathrm{p}}^{2}=.97$, with a trend towards a greater differentiation in the IE condition, $F(1,46)=3.33, p=.08, \eta_{\mathrm{p}}^{2}=.07$.

Effectiveness of the manipulation: In the NE condition, differential US expectancies did not change from the last acquisition trial to the first extinction trial, as shown by a non-significant $\mathrm{CS} \times \mathrm{T}$ (ACQ5 vs. EXT1) interaction, $F(1,23)=2.59, p=.12, \eta_{\mathrm{p}}^{2}=.10$. In contrast, in the IE condition, US expectancies reduced from acquisition to extinction, $F(1,23)=446.96, p<.001, \eta_{\mathrm{p}}^{2}=.95$. In this condition, analyses indicated a trend towards a CS + vs. CS - differentiation on the first extinction trial, $F(1,23)=3.15, p=.09, \eta_{\mathrm{p}}^{2}=.12$, this differentiation being non-significant on the second extinction trial, $F(1,23)=1.86$, $p=.19, \eta_{\mathrm{p}}^{2}=.08$. Thus, the extinction instruction was effective: it resulted in an almost-immediate and complete reduction in differential US expectancies.

Extinction: In the $\mathrm{NE}$ condition, differential expectancies diminished during extinction $(\mathrm{CS} \times \mathrm{T}), F(3.79,87.22)=42.56$, $p<.001, \eta_{\mathrm{p}}^{2}=.65$, while unsurprisingly, this was not the case for the IE condition, $F(2.05,47.23)=1.64, p=.20, \eta_{\mathrm{p}}^{2}=.07$. On extinction trial 12, a significant differentiation remained in the NE condition, $F(1,23)=11.01, p=.003, \eta_{\mathrm{p}}^{2}=.32$, but not in the IE condition, $F<1$.

Spontaneous recovery and re-extinction: Spontaneous recovery of US expectancies was present (EXT12 vs. RE-EXT1), $F(1,46)=86.83$, $p<.001, \eta_{\mathrm{p}}^{2}=.65$, and similar across conditions, $F<1$. In line with this, on re-extinction trial 1 a significant differentiation in US expectancies was found, $F(1,46)=150.15, p<.001, \eta_{\mathrm{p}}^{2}=.77$, that did not differ between conditions, $F<1$. Expectancies re-extinguished $(\mathrm{CS} \times \mathrm{T}), F(2.89,132.92)=55.76, p<.001, \eta_{\mathrm{p}}^{2}=.55$, although a significant differentiation remained on the last re-extinction trial, $F(1,46)=10.12, p=.003, \eta_{\mathrm{p}}^{2}=.18$. Conditions did not differ in the course of re-extinction $(\mathrm{CS} \times \mathrm{T} \times \mathrm{C}$ ) and in final re-extinction levels, $F s<1$. Thus, overall, US expectancies recovered after a $24 \mathrm{~h}$ interval and re-extinguished to a certain extent, but no differences across conditions were found.

\subsection{Desire to eat chocolate}

Acquisition: Participants acquired a differential desire to eat chocolate during acquisition $(\mathrm{CS} \times \mathrm{T}), F(2.33,107.16)=4.89$, $p=.006, \eta_{\mathrm{p}}^{2}=.10$, and equally so for both conditions $(\mathrm{CS} \times \mathrm{T} \times \mathrm{C})$, $F<1$ (see Fig. 2). This resulted in a significantly higher desire to eat in response to the CS + vs. the CS - on the last acquisition trial, $F(1$, $46)=29.92, p<.001, \eta_{\mathrm{p}}^{2}=.39$, independent of condition, $F<1$.

Immediate response to the manipulation: The explicit CS-US disconfirmation did not appear to reduce differential desires to eat on the subsequent trial. Although differential desires diminished marginally significant from the last acquisition to the first extinction trial, $F(1,46)=3.74, p=.06, \eta_{\mathrm{p}}^{2}=.08$, importantly, this change did not interact with condition, $F=1.21$, $n s$. A significant CS+ vs. CS - differentiation was still present on the first extinction trial, $F(1$, $46)=17.40, p<.001, \eta_{\mathrm{p}}^{2}=.27$, independent of condition, $F<1$.

Because visual inspection of the figures suggested an overall decrease in eating desires in specifically the IE condition, additional analyses were performed on the overall change in eating desires (ACQ5 vs EXT1). These confirmed an overall reduction in desires in the IE condition, $F(1,23)=10.51, p=.004, \eta_{\mathrm{p}}^{2}=.31$, but not in the NE condition, $F<1$ (overall T $\times C$ interaction: $F(1,46)=4.37, p=.04$, $\eta_{\mathrm{p}}^{2}=.09$ ). Thus, while disconfirmation of US expectancies did not affect conditioned desires to eat, it appeared to diminish eating desires overall.

Extinction: Conditioned desires to eat extinguished $(\mathrm{CS} \times \mathrm{T})$,

Table 1

Participants characteristics per condition; means with standard deviations in parentheses.

\begin{tabular}{|c|c|c|c|c|}
\hline & Normal extinction $(N=24)$ & Instructed extinction $(N=24)$ & $t(46)$ & $p$ \\
\hline Age & $19.38(1.47)$ & $19.21(1.28)$ & 0.42 & .68 \\
\hline BMI & $23.45(4.81)$ & $22.96(3.03)$ & 0.43 & .67 \\
\hline \multicolumn{5}{|c|}{ Baseline hunger } \\
\hline Session 1 & $36.21(19.38)$ & $48.00(22.32)$ & 1.95 & .06 \\
\hline Session 2 & $41.46(26.73)$ & $48.29(27.18)$ & 0.88 & .38 \\
\hline US liking & $76.58(10.50)$ & $75.71(16.31)$ & 0.05 & .83 \\
\hline \multicolumn{5}{|l|}{ DEBQ } \\
\hline Restrained & $2.70(0.73)$ & $2.77(0.69)$ & 0.35 & .73 \\
\hline Emotional & $2.53(0.65)$ & $2.68(0.53)$ & 0.88 & .38 \\
\hline External & $3.26(0.59)$ & $3.21(0.59)$ & 0.27 & .79 \\
\hline
\end{tabular}




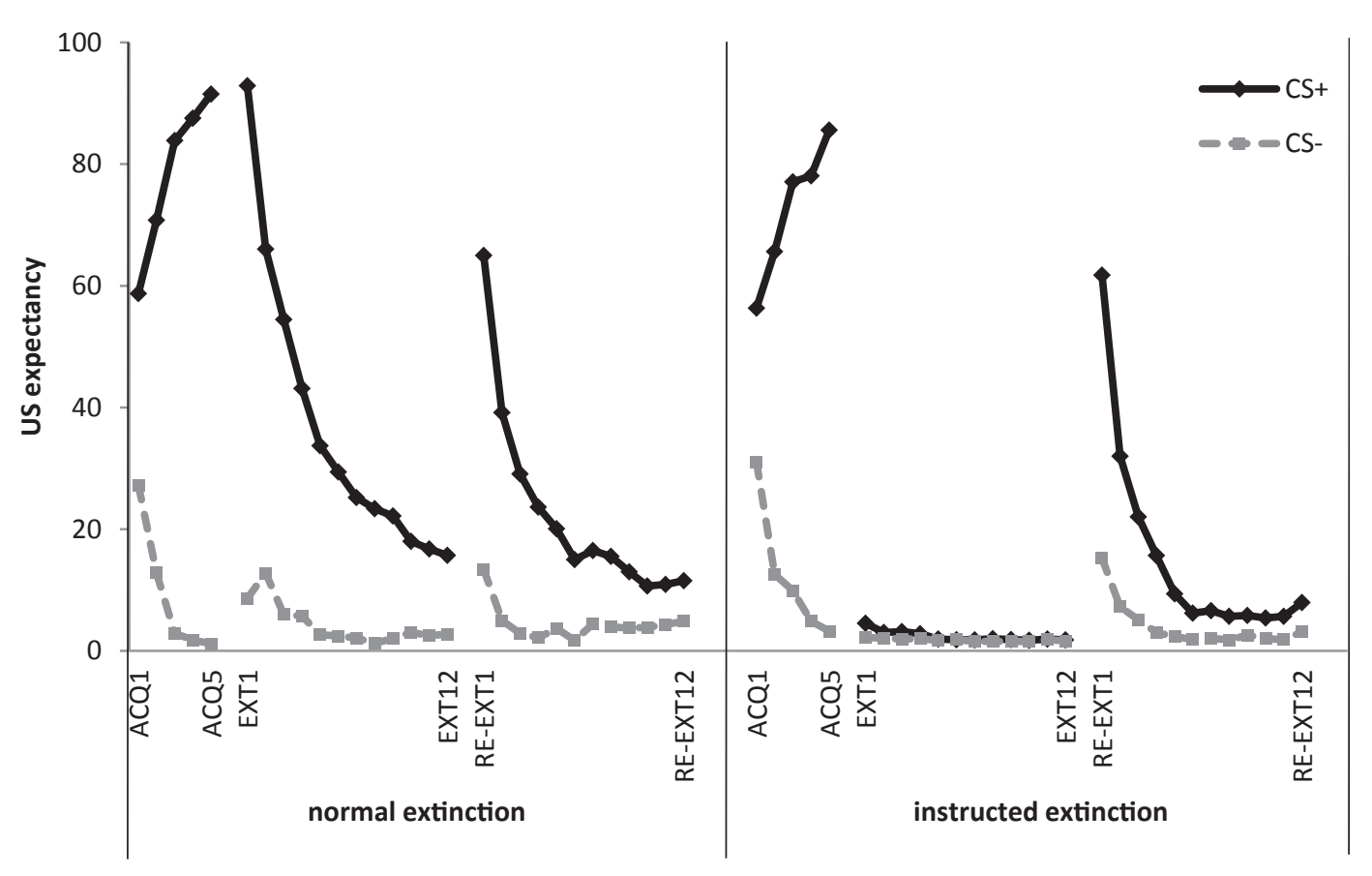

Fig. 1. Mean US expectancy by CS-type, trial, condition, and phase of the experiment.

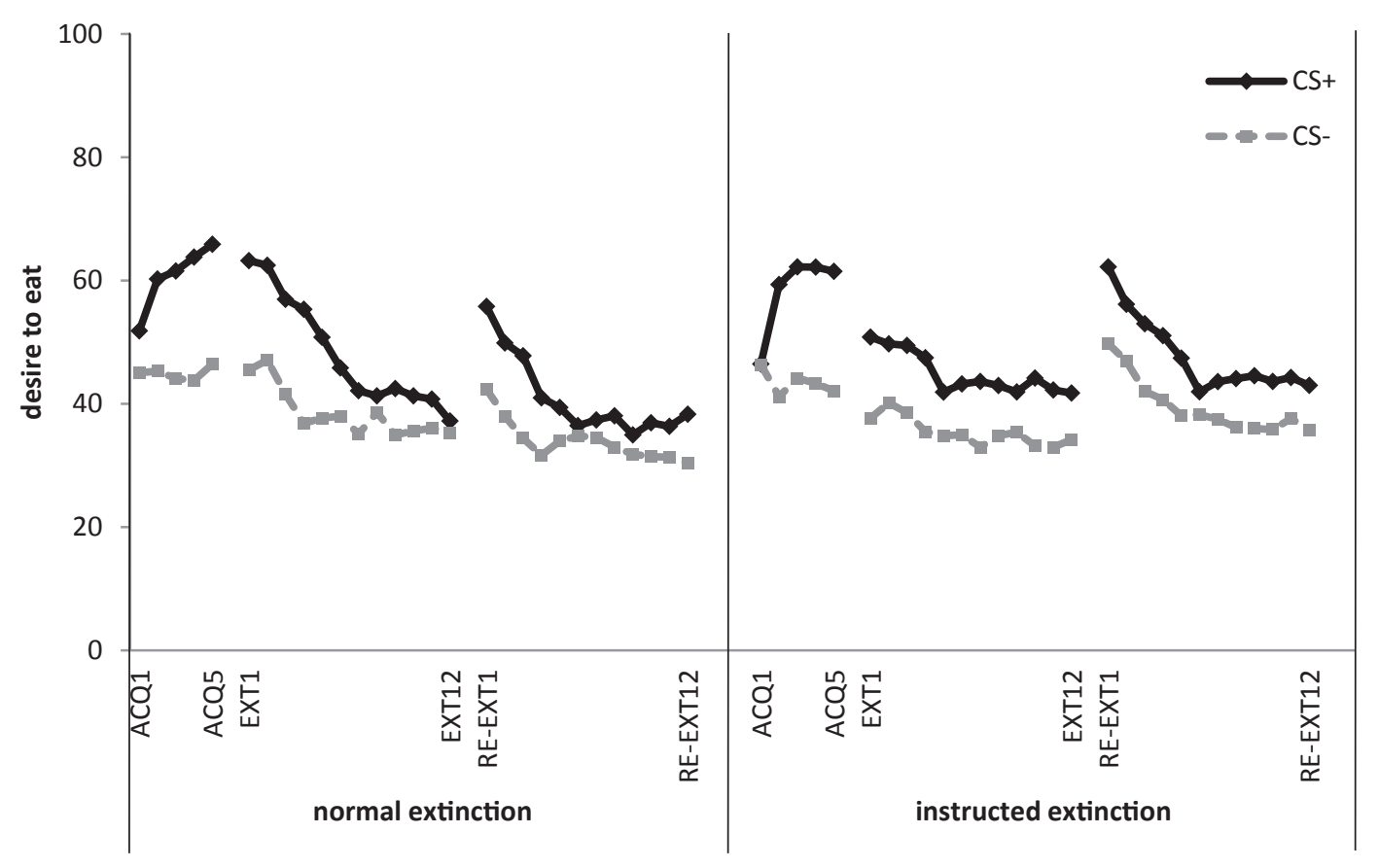

Fig. 2. Mean desire to eat by CS-type, trial, condition, and phase of the experiment.

$F(3.42,157.17)=2.85, p=.033, \eta_{\mathrm{p}}^{2}=.06$, and similarly so across conditions $(\mathrm{CS} \times \mathrm{T} \times \mathrm{C}), F(3.42,157.17)=1.35, p=.26, \eta_{\mathrm{p}}^{2}=.03$. Extinction of differential desires to eat was not complete: a marginally significant differentiation between the CS + and CSremained at the end of extinction (ext12), $F(1,46)=3.91, p=.054$, $\eta_{\mathrm{p}}^{2}=.08$, with no differences across conditions, $F(1,46)=1.41$, $p=.24, \eta_{\mathrm{p}}^{2}=.03$.

Spontaneous recovery and re-extinction: Conditioned desires recovered after a 24 h delay (EXT12 vs RE-EXT1), $F(1,46)=6.58$, $p=.014, \eta_{\mathrm{p}}^{2}=.13$, and this was similar across conditions, $F=1.08$, ns. This resulted in a significant $\mathrm{CS}+$ vs $\mathrm{CS}-$ differentiation on the first re-extinction trial, $F(1,46)=24.13, p<.001, \eta_{\mathrm{p}}^{2}=.34$, that was similar across conditions, $F<1$. Conditioned desires reextinguished to some extent $(\mathrm{CS} \times \mathrm{T}), F(5.46,251.08)=3.80$, $p=.002, \eta_{\mathrm{p}}^{2}=.08$, with no differences across conditions $(\mathrm{CS} \times \mathrm{T} \times \mathrm{C}), F<1$. Again, extinction was not complete: the differential desire to eat was still significant on the last re-extinction trial, $F(1,46)=13.81, p=.001, \eta_{\mathrm{p}}^{2}=.23$, and similarly for both conditions, $F<1$. 


\subsection{CS evaluations}

After acquisition, the CS+ was evaluated significantly more positively than the CS-, $F(1,46)=23.13, p<.001, \eta_{\mathrm{p}}^{2}=.34$ (see Fig. 3). This differential conditioned evaluation extinguished, $F(1$, $46)=14.80, p<.001, \eta_{\mathrm{p}}^{2}=.24$, though after extinction there was still a trend towards more positive evaluations for the CS + vs CS-, $F(1,46)=2.86, p=.1, \eta_{\mathrm{p}}^{2}=.06$. The conditions did not differ in the acquisition or extinction of conditioned evaluations, $F s<1$.

Differential conditioned evaluations recovered during tests at the beginning of the second session (EXT vs RE-EXT PRE), $F(1$, $46)=16.10, p<.001, \eta_{\mathrm{p}}^{2}=.26$, and again resulting in significantly higher evaluations for the CS+ vs CS - before re-extinction, $F(1$, $46)=17.22, p<.001, \eta_{\mathrm{p}}^{2}=.27$. Again, evaluations extinguished, $F(1$, $46)=27.57, p<.001, \eta_{\mathrm{p}}^{2}=.38$, and this time, extinction was complete, $F<1$. Spontaneous recovery, the course of extinction, and final extinction levels did not differ significantly across conditions, $F<1, F(1,46)=2.11, p=.15, \eta_{\mathrm{p}}^{2}=.04 ; F(1,46)=1.81, p=.19$, $\eta_{\mathrm{p}}^{2}=.04$.

\subsection{Correlational analyses}

At the end of acquisition, differential evaluations correlated only with eating desires, $r(48)=.32, p=.03$. Correlations between US expectancies and evaluations, $r(48)=.03, n s$, and US expectancies and eating desires were non-significant, $r(48)=.24, p=.11$. Similarly, after extinction, conditioned evaluations correlated significantly with differential eating desires, $r(48)=.43, p=.002$, while US expectancies did not correlate with evaluations, $r(48)=-.01, n s$, nor with eating desires, $r(48)=.06, n s$. Thus, on session 1 , it seems that conditioned evaluations are linked with eating desires while US expectancies are not. At the start of re-extinction, differential desires correlated with both US expectancies, $r(48)=.33, p=.02$ and conditioned evaluations, $r(48)=.38, p=.008$, which also correlated with each other, $r(48)=.28, p=.051$. After re-extinction, evaluations did not correlate with eating desires, $r(48)=.20$, $p=.18$, nor with US expectancies: $r(48)=-.17, p=.25$, while this time, US expectancies were inversely correlated with eating desires, $r(48)=-.37, p=.01$.
In sum, on session 1, greater positive evaluations of the $\mathrm{CS}+$ (but not heightened US expectancies) appeared to consistently co-occur with increased eating desires. A different pattern was found on session 2: at the start of re-extinction, eating desires correlated with both conditioned evaluations and US expectancies. After reextinction, differential eating desires did not correlate with conditioned evaluations and even showed an inverse correlation with US expectancies. Thus, overall, findings of correlational analyses were somewhat mixed but suggest eating desires to be more related to conditioned evaluations than to US expectancies.

\section{Discussion}

The aim of the present study was to examine whether instructed extinction would affect the short-term and longer-term extinction of conditioned appetitive responses. In addition, the relationship between eating desires, eating expectancies, and CS evaluations was examined. It was found that disconfirming eating expectancies prior to extinction did not affect the short-term extinction of conditioned eating desires: in both conditions, differential desires reduced but did not extinguish completely. On session 2, spontaneous recovery and re-extinction of appetitive responses was found, while again, this was similar across the conditions. CS evaluations correlated with eating desires on session 1, but not on session 2 .

The finding that on session 1 , an explicit disconfirmation of eating expectancies did not affect the short-term extinction of eating desires suggests that eating expectancy does not act as mediator for the extinction of eating desires. Hence, it seems unlikely that previously observed difficulties to extinguish eating desires were caused by a lack of complete extinction of eating expectancies. This is in line with the idea that eating expectancies and eating desires stem from loosely coupled response systems that are differentially susceptible to extinction (Delamater \& Westbrook, 2014). As described in the Introduction, one possibility is that eating desires and conditioned evaluations share a common mechanism, which would cause them to behave similarly throughout the different conditioning phases. Only partial evidence was found for this in the present study. On session 1, conditioned

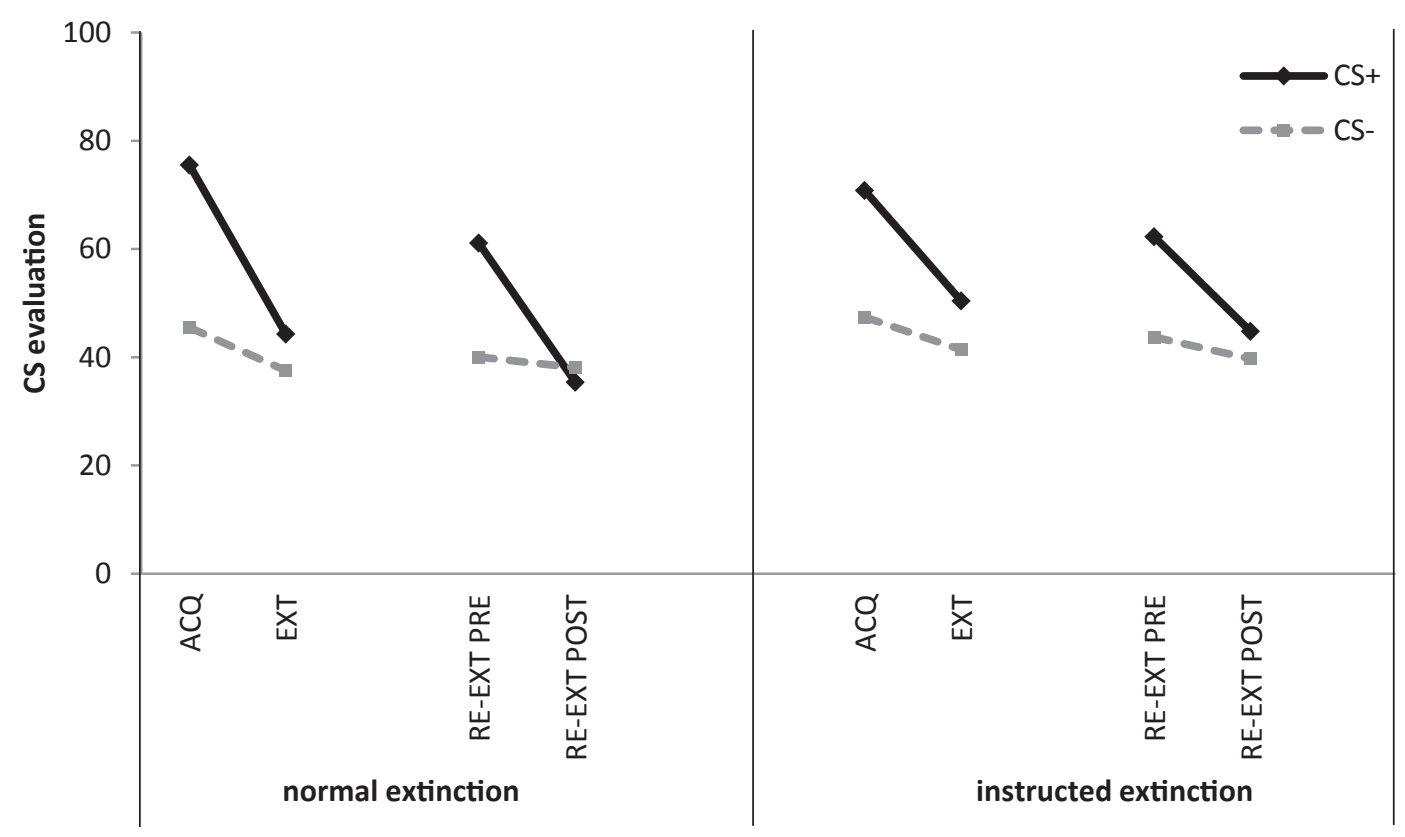

Fig. 3. Mean CS evaluation by CS-type, condition, and phase of the experiment. 
evaluations and eating desires appeared to co-occur: both evaluations and eating desires seemed equally unaffected by instructed extinction, and differential acquisition and extinction of eating desires correlated with the differential acquisition and extinction of evaluations, but not with differential expectancies. In contrast however, on session 2, no evidence was found for eating desires to be more closely linked to evaluations than to eating expectancies. Thus, overall, our findings provide some evidence for eating desires to be associated more closely with conditioned evaluations than with US expectancies, although they also do not seem to behave in synchrony. The partial concordance between eating desires and evaluations may be explained by eating desires and CS evaluations being based on activation of the US representation in memory, reflecting a mere referential learning that is not dependent on current eating expectancies (Hermans et al., 2002). Their partial discordance however suggests that eating desires and evaluations are not homologous either. Alternatively, it may be that our selfreport measure of CS evaluations did not provide accurate measures of underlying evaluative representations, but were influenced by judgment-related processes, contributing to divergences between eating desires and evaluations. Specifically, prior judgments of CS evaluations (i.e., after acquisition) may cause participants to use the most recent information rather than integrating all available information about the CS: there is evidence for (partial) extinction of CS evaluations to occur only when the CSs are also rated after acquisition (Gawronski, Gast, \& De Houwer, 2014; Lipp \& Purkis, 2006). This could also account for the relative ease of extinguishing conditioned evaluations in the current study. Including reliable behavioural and physiological measures of appetitive responding in future studies may help clarify correlates of different response systems involved in appetitive conditioning (Van Gucht, Vansteenwegen, Beckers, \& Van den Bergh, 2008a; Van den Akker et al., 2014).

Of note, the finding that instructed extinction did not affect the short-term extinction of eating desires on session 1 seems at odds with a study in smokers in which instructed extinction immediately eliminated conditioned cigarette cravings (Field \& Duka, 2001). It may be that US expectancies differentially affect appetitive responses to food vs drug cues. In cue reactivity studies, in which participants are exposed to the sight and/or smell of drugs or food, heightening use or consumption expectancies often results in an increase in drug craving (see Jędras, Jones, \& Field, 2014), while food craving appears unaffected (Hardman, Scott, Field, \& Jones, 2014; Werthmann, Roefs, Nederkoorn, \& Jansen, 2013). The causes for these differential patterns are presently unclear.

A well-known finding in animal studies is that extinguished appetitive responses to food cues can easily return in certain situations. It is thought that in humans, such returns of responses can promote a full-blown relapse and undermine the long-term effectiveness of exposure therapy and other weight loss efforts or treatments (Bouton, 2011). Translational studies on this topic are however very sparse. The present study adds to this field by showing that conditioned responses such as eating desires can spontaneously recover after the mere passage of time. This finding highlights the importance of relapse prevention in cue exposure (and other weight loss) therapy, which can be achieved by incorporating techniques that reduce returns of responses caused by, for instance, spontaneous recovery. One of these potential techniques was investigated in the present study: less spontaneous recovery and re-extinction were expected after normal vs instructed extinction because of heightened expectancy violation in case of normal extinction (Craske et al., 2014). The finding that the groups did not differ in their longer-term extinction of eating desires suggests that expectancy violation is not as important for reducing conditioned eating desires as it is in the fear domain for reducing conditioned fear (Craske et al., 2014; Salkovskis, Hackmann, Wells, Gelder, \& Clark, 2006). Although further studies are needed, the clinical implication would be that it might not be necessary to focus on expectancy violation in CET to reduce eating desires. Since CET does seem effective in reducing food cravings, it may be that mechanisms other than expectancy violation underlie its effectiveness. Alternatively, it is also possible that the returns of responses caused by spontaneous recovery were too strong to detect any effects of our manipulation. Perhaps a larger number of extinction sessions is needed for group differences to emerge, or effects on extinction learning would be reflected in other measures of appetitive responding. In any case, further research on the longterm extinction of appetitive responses to food cues in humans is clearly needed.

Our findings raise the question how one might effectively extinguish conditioned eating desires. If conditioned evaluations and eating desires share a common mechanism, one approach would be to use methods that have been shown to be effective in changing conditioned evaluations. For instance, counterconditioning (pairing the CS + with a US of opposite valence) has been shown to eliminate acquired evaluations (Baeyens, Eelen, van den Bergh, \& Crombez, 1989), as well as conditioned cravings for chocolate (Van Gucht et al., 2010). Other effective methods may include a more extensive extinction training (Luck \& Lipp, 2015), US devaluation (decreasing the evaluative meaning of the US) (e.g., Baeyens, Eelen, Van den Bergh, \& Crombez, 1992; Leer, Engelhard, Altink, \& van den Hout, 2013), or cognitive reappraisal of the CS (Blechert et al., 2015). Interestingly, and underlining the potential benefit of changing conditioned evaluations, (manipulating) CS evaluations has been found to be predictive for food choice (Veling, Aarts, \& Stroebe, 2013), alcohol intake (Houben, Nederkoorn, Wiers, \& Jansen, 2011), and for reinstatement of conditioned fear (Zbozinek, Hermans, Prenoveau, Liao, \& Craske, 2014).

In sum, it was found that eating expectancies did not mediate the extinction of eating desires, nor did greater expectancy violation during extinction enhance extinction learning. Eating desires appeared only partially linked with conditioned evaluations. One implication could be that in CET, it is not necessary to attempt maximizing the violation of eating expectancies. Future research may aim to confirm that increased violation of eating expectancies is, indeed, not effective in reducing eating desires during CET. In addition, future studies may examine how successful long-term extinction of conditioned appetitive responses such as eating desires can be optimized, and in which manners these techniques can be implemented in weight loss therapies.

\section{Acknowledgements}

This study is part of an ongoing project that is financed by the Netherlands Organisation for Scientific Research (NWO): Vici Grant 453.10.006, awarded to Anita Jansen.

\section{References}

Baeyens, F., Crombez, G., Van den Bergh, O., \& Eelen, P. (1988). Once in contact always in contact: evaluative conditioning is resistant to extinction. Advances in Behaviour Research and Therapy, 10(4), 179-199. http://dx.doi.org/10.1016/01466402(88)90014-8.

Baeyens, F., Eelen, P., Crombez, G., \& Van den Bergh, O. (1992). Human evaluative conditioning: acquisition trials, presentation schedule, evaluative style and contingency awareness. Behaviour Research and Therapy, 30(2), 133-142. http:// dx.doi.org/10.1016/0005-7967(92)90136-5.

Baeyens, F., Eelen, P., van den Bergh, O., \& Crombez, G. (1989). Acquired affectiveevaluative value: conservative but not unchangeable. Behaviour Research and Therapy, 27(3), 279-287. http://dx.doi.org/10.1016/0005-7967(89)90047-8.

Baeyens, F., Eelen, P., Van den Bergh, O., \& Crombez, G. (1992). The content of learning in human evaluative conditioning: acquired valence is sensitive to USrevaluation. Learning and Motivation, 23(2), 200-224. http://dx.doi.org/10.1016/ 
0023-9690(92)90018-H.

Berghofer, A., Pischon, T., Reinhold, T., Apovian, C., Sharma, A., \& Willich, S. (2008) Obesity prevalence from a European perspective: a systematic review. BMC Public Health, 8(1), 200. http://dx.doi.org/10.1186/1471-2458-8-200.

Blechert, J., Wilhelm, F. H., Williams, H., Braams, B. R., Jou, J., \& Gross, J. J. (2015) Reappraisal facilitates extinction in healthy and socially anxious individuals. Journal of Behavior Therapy and Experimental Psychiatry, 46(0), 141-150. http:// dx.doi.org/10.1016/j.jbtep.2014.10.001.

Bongers, P., van den Akker, K., Havermans, R., \& Jansen, A. (2015). Emotional eating and Pavlovian learning: does negative mood facilitate appetitive conditioning? Appetite, 89(0), 226-236. http://dx.doi.org/10.1016/j.appet.2015.02.018.

Boutelle, K. N., Zucker, N., Peterson, C. B., Rydell, S., Carlson, J., \& Harnack, L. J. (2014) An intervention based on Schachter's externality theory for overweight children: the regulation of cues pilot. Journal of Pediatric Psychology, 39(4), 405-417. http://dx.doi.org/10.1093/jpepsy/jst142.

Bouton, M. E. (2011). Learning and the persistence of appetite: extinction and the motivation to eat and overeat. Physiology \& Behavior, 103(1), 51-58. http:/ dx.doi.org/10.1016/j.physbeh.2010.11.025.

Craske, M. G., Treanor, M., Conway, C. C., Zbozinek, T., \& Vervliet, B. (2014). Maximizing exposure therapy: an inhibitory learning approach. Behaviour Research and Therapy, 58(0), 10-23. http://dx.doi.org/10.1016/j.brat.2014.04.006.

Delamater, A. R., \& Westbrook, R. F. (2014). Psychological and neural mechanisms of experimental extinction: a selective review. Neurobiology of Learning and Memory, 108, 38-51. http://dx.doi.org/10.1016/j.nlm.2013.09.016.

Fedoroff, I., Polivy, J., \& Peter Herman, C. (2003). The specificity of restrained versus unrestrained eaters' responses to food cues: general desire to eat, or craving for the cued food? Appetite, 41(1), 7-13. http://dx.doi.org/10.1016/S0195-6663(03) 00026-6.

Ferriday, D., \& Brunstrom, J. M. (2011). 'I just can't help myself': effects of food-cue exposure in overweight and lean individuals. International Journal of Obesity (London), 35(1), 142-149. http://dx.doi.org/10.1038/ijo.2010.117.

Field, M., \& Duka, T. (2001). Smoking expectancy mediates the conditioned responses to arbitrary smoking cues. Behavioural Pharmacology, 12(3), 183-194.

Gawronski, B., Gast, A., \& De Houwer, J. (2014). Is evaluative conditioning really resistant to extinction? Evidence for changes in evaluative judgements without changes in evaluative representations. Cognition and Emotion, 29(5), 1-15. http://dx.doi.org/10.1080/02699931.2014.947919.

Hardman, C. A., Scott, J., Field, M., \& Jones, A. (2014). To eat or not to eat. The effects of expectancy on reactivity to food cues. Appetite, 76, 153-160. http:/ dx.doi.org/10.1016/j.appet.2014.02.005.

Hermans, D., Vansteenwegen, D., Crombez, G., Baeyens, F., \& Eelen, P. (2002). Expectancy-learning and evaluative learning in human classical conditioning: affective priming as an indirect and unobtrusive measure of conditioned stimulus valance. Behaviour Research and Therapy, 40, 217-234.

Houben, K., Nederkoorn, C., Wiers, R. W., \& Jansen, A. (2011). Resisting temptation: decreasing alcohol-related affect and drinking behavior by training response inhibition. Drug and Alcohol Dependence, 116, 132-136. http://dx.doi.org 10.1016/j.drugalcdep.2010.12.011.

Jansen, A. (1998). A learning model of binge eating: cue reactivity and cue exposure. Behaviour Research and Therapy, 36(3), 257-272. http://dx.doi.org/10.1016 S0005-7967(98)00055-2.

Jansen, A., Broekmate, J., \& Heymans, M. (1992). Cue-exposure vs self-control in the treatment of binge eating: a pilot study. Behaviour Research and Therapy, 30(3) 235-241. http://dx.doi.org/10.1016/0005-7967(92)90069-S.

Jansen, A., Havermans, R., \& Nederkoorn, C. (2011). Cued overeating. In V. R. Preedy, R. R. Watson, \& C. R. Martin (Eds.), Handbook of behavior, food and nutrition (pp. 1431-1443). New York: Springer.

Jansen, A., Stegerman, S., Roefs, A., Nederkoorn, C., \& Havermans, R. (2010). Decreased salivation to food cues in formerly obese successful dieters. Psychotherapy and Psychosomatics, 79(4), 257-258. http://dx.doi.org/10.1159/ 000315131.

Jansen, A., Theunissen, N., Slechten, K., Nederkoorn, C., Boon, B., Mulkens, S., et al. (2003). Overweight children overeat after exposure to food cues. Eating Behaviors, 4(2), 197-209. http://dx.doi.org/10.1016/S1471-0153(03)00011-4.

Jansen, A., Van Den Hout, M. A., De Loof, C., Zandbergen, J., \& Griez, E. (1989). A case of bulimia successfully treated by cue exposure. Journal of Behavior Therapy and Experimental Psychiatry, 20(4), 327-332. http://dx.doi.org/10.1016/00057916(89)90064-5.

Jędras, P., Jones, A., \& Field, M. (2014). The role of anticipation in drug addiction and reward. Clinical, Cosmetic and Investigational Dentistry, 6, 45-56. http:// dx.doi.org/10.2147/NAN.S35917.

Karhunen, L. J., Lappalainen, R. I., Tammela, L., Turpeinen, A. K., \& Uusitupa, M. I. J. (1997). Subjective and physiological cephalic phase responses to food in obese binge-eating women. International Journal of Eating Disorders, 21(4), 321-328. doi: 10.1002/(SICI)1098-108X(1997)21:4<321::AID-EAT3>3.0.CO;2-Q.

Leer, A., Engelhard, I. M., Altink, A., \& van den Hout, M. A. (2013). Eye movements during recall of aversive memory decreases conditioned fear. Behaviour Research and Therapy, 51(10), 633-640. http://dx.doi.org/10.1016/ j.brat.2013.07.004.
Lipp, O. V., \& Purkis, H. M. (2006). The effects of assessment type on verbal ratings of conditional stimulus valence and contingency judgments: implications for the extinction of evaluative learning. Journal of Experimental Psychology: Animal Behavior Processes, 32, 431-440. http://dx.doi.org/10.1037/0097-7403.32.4.431.

Luck, C. C., \& Lipp, O. V. (2015). A potential pathway to the relapse of fear? Conditioned negative stimulus evaluation (but not physiological responding) resists instructed extinction. Behaviour Research and Therapy, 66, 18-31. http:// dx.doi.org/10.1016/j.brat.2015.01.001.

Martinez-Mallén, E., Castro-Fornieles, J., Lázaro, L., Moreno, E., Morer, A., Font, E., \& Toro, J. (2007). Cue exposure in the treatment of resistant adolescent bulimia nervosa. International Journal of Eating Disorders, 40(7), 596-601. http:// dx.doi.org/10.1002/eat.20423.

McGaugh, J. L. (2000). Memory-a century of consolidation. Science, 287(5451), 248-251. http://dx.doi.org/10.1126/science.287.5451.248.

Ogden, C. L., Carroll, M. D., Kit, B. K., \& Flegal, K. M. (2014). Prevalence of childhood and adult obesity in the united states, 2011-2012. JAMA, 311(8), 806-814. http://dx.doi.org/10.1001/jama.2014.732.

Pavlov, I. P. (1927). Conditioned reflexes. New York: Dover.

Rescorla, R. A. (2004). Spontaneous recovery. Learning \& Memory, 11(5), 501-509. http://dx.doi.org/10.1101/lm.77504.

Rescorla, R. A., \& Wagner, A. R. (1972). A theory of Pavlovian conditioning: variations in the effectiveness of reinforcement and non-reinforcement. In A. H. Prokasy (Ed.), Classical conditioning II: Current research and theory (pp. 64-99). New York: Appleton-Century-Croft.

Salkovskis, P. M., Hackmann, A., Wells, A., Gelder, M. G., \& Clark, D. M. (2006). Belief disconfirmation versus habituation approaches to situational exposure in panic disorder with agoraphobia: a pilot study. Behaviour Research and Therapy, 45, 877-885. http://dx.doi.org/10.1016/j.brat.2006.02.008.

Schyns, G. L. T., Roefs, A., Mulkens, S., \& Jansen, A. (2016). Expectancy violation, reduction of food cue reactivity and less eating in the absence of hunger after one food cue exposure session for overweight and obese women. Behaviour Research and Therapy, 76, 57-64. http://dx.doi.org/10.1016/j.brat.2015.11.007.

Sevenster, D., Beckers, T., \& Kindt, M. (2012). Instructed extinction differentially affects the emotional and cognitive expression of associative fear memory. Psychophysiology, 49(10), 1426-1435. http://dx.doi.org/10.1111/j.14698986.2012.01450.x

Toro, J., Cervera, M., Feliu, M. H., Garriga, N., Jou, M., Martinez, E., et al. (2003). Cue exposure in the treatment of resistant bulimia nervosa. International Journal of Eating Disorders, 34, 227-234. http://dx.doi.org/10.1002/eat.10186.

Van Gucht, D., Baeyens, F., Vansteenwegen, D., Hermans, D., \& Beckers, T. (2010). Counterconditioning reduces cue-induced craving and actual cue-elicited consumption. Emotion, 10(5), 688. http://dx.doi.org/10.1037/a0019463.

Van Gucht, D., Vansteenwegen, D., Beckers, T., \& Van den Bergh, O. (2008a). Return of experimentally induced chocolate craving after extinction in a different context: divergence between craving for and expecting to eat chocolate. Behaviour Research and Therapy, 46(3), 375-391. http://dx.doi.org/10.1016/ j.brat.2008.01.003.

Van Gucht, D., Vansteenwegen, D., Van den Bergh, O., \& Beckers, T. (2008b). Conditioned craving cues elicit an automatic approach tendency. Behaviour Research and Therapy, 46(10), 1160-1169. http://dx.doi.org/10.1016/ j.brat.2008.05.010.

Van Strien, T., Frijters, J. E., Bergers, G., \& Defares, P. B. (1986). The Dutch eating behavior questionnaire (DEBQ) for assessment of restrained, emotional, and external eating behavior. International Journal of Eating Disorders, 5(2), 295-315, 10.1002/1098-108X(198602)5:2<295::AID-EAT2260050209>3.0.CO;2-T.

Van den Akker, K., Havermans, R. C., Bouton, M. E., \& Jansen, A. (2014). How partial reinforcement of food cues affects the extinction and reacquisition of appetitive responses. A new model for dieting success? Appetite, 81(0), 242-252. http:/ dx.doi.org/10.1016/j.appet.2014.06.024.

Van den Akker, K., Havermans, R. C., \& Jansen, A. (2015). Effects of occasional reinforced trials during extinction on the reacquisition of conditioned responses to food cues. Journal of Behavior Therapy and Experimental Psychiatry, 48, 50-58. http://dx.doi.org/10.1016/j.jbtep.2015.02.001.

Van den Akker, K., Jansen, A., Frentz, F., \& Havermans, R. C. (2013). Impulsivity makes more susceptible to overeating after contextual appetitive conditioning. Appetite, 70(0), 73-80. http://dx.doi.org/10.1016/j.appet.2013.06.092.

Veling, H., Aarts, H., \& Stroebe, W. (2013). Stop signals decrease choices for palatable foods through decreased food evaluation. Frontiers in Psychology, 4, 875. http:// dx.doi.org/10.3389/fpsyg.2013.00875.

Wardle, J. (1990). Conditioning processes and cue exposure in the modification of excessive eating. Addictive Behaviors, 15(4), 387-393. http://dx.doi.org/10.1016/ 0306-4603(90)90047-2.

Werthmann, J., Roefs, A., Nederkoorn, C., \& Jansen, A. (2013). Desire lies in the eyes: attention bias for chocolate is related to craving and self-endorsed eating permission. Appetite, 70, 81-89. http://dx.doi.org/10.1016/j.appet.2013.06.087.

Zbozinek, T. D., Hermans, D., Prenoveau, J. M., Liao, B., \& Craske, M. G. (2014). Postextinction conditional stimulus valence predicts reinstatement fear: relevance for long-term outcomes of exposure therapy. Cognition and Emotion, 29(4), 654-667. http://dx.doi.org/10.1080/02699931.2014.930421. 